\title{
Effect of probucol on hemodynamics, rheology and blood lipid of diabetic retinopathy
}

\author{
HONG LIU and MINGMING CAI
}

\begin{abstract}
Department of Ophthalmology, The Ninth People's Hospital of Chongqing, Chongqing 400700, P.R. China
\end{abstract}
Received October 13, 2017; Accepted January 22, 2018

DOI: $10.3892 / \mathrm{etm} .2018 .5917$

\begin{abstract}
The effect of probucol in the treatment of diabetic retinopathy was investigated to analyze its impact on its hemodynamics, rheology and blood lipid. A total of 80 patients with diabetic retinopathy who were treated in the Ninth People's Hospital of Chongqing (Chongqing, China) from January 2015 to August 2016 were selected and divided into two groups by random number table, with 40 patients in each group. Control group was treated by conventional and intensive glycemic control and antihypertensive therapy, while observation group was orally administered with $0.375 \mathrm{~g}$ probucol twice a day on the basis of intensive therapy. Outpatient follow-up was performed to all the patients for 6 months, then, among the blood rheology, the changes in blood viscosity and erythrocyte aggregation indexes at different time points before and after intervention in the two groups were compared, mean blood flow velocities in renal artery, renal artery pulse indexes and renal artery resistance indexes at different time points were recorded, changes in blood lipid of the two groups before and after intervention were compared, and complication rates during the treatment were calculated. After intervention, the whole blood viscosity at high shear rate, whole blood viscosity at low shear rate and plasma viscosity in observation group were lower than those before intervention and lower than those in control group after intervention $(\mathrm{P}<0.05)$; The erythrocyte aggregation indexes in observation group were obviously increased compared with those in control group at 1 week, 1 month and 6 months after intervention $(\mathrm{P}<0.05)$. The mean blood flow velocities in renal artery in observation group were remarkably higher than those in control group at 1 week, 1 month and 6 months after intervention $(\mathrm{P}<0.05)$, while the renal artery pulse indexes and resistance indexes in observation group were lower than those in control group
\end{abstract}

Correspondence to: Dr Mingming Cai, Department of Ophthalmology, The Ninth People's Hospital of Chongqing, 69 Jia Ling Road, Chongqing 400700, P.R. China

E-mail: luhewentan@163.com

Key words: probucol, diabetic retinopathy, hemodynamics, blood rheology, blood lipids in the same period $(\mathrm{P}<0.05)$. In observation group, the levels of total cholesterol (TC), triglyeride (TG) and low density lipoprotein cholesterol (LDL-C) after intervention were decreased compared with those before intervention, while the level of high-density lipoprotein cholesterol (HDL-C) was increased. The levels of TC, TG and LDL-C in observation group were lower than those in control group after intervention, while the HDL-C level was higher $(\mathrm{P}<0.05)$. During the treatment, the total incidence of phlebitis, chills, fever, rash and maculopapule in observation group was obviously lower than that in control group. Probucol can significantly improve the hemodynamic and rheological indexes and lower blood lipid in the body, and is an effective medicine for diabetic retinopathy.

\section{Introduction}

Diabetic retinopathy is one of the common complications in patients with advanced diabetes, which is the main cause for patient's hypopsia and even blindness (1). With the change in eating habits and lifestyle of the Chinese people, the incidence rate of diabetes is rising significantly. Some studies indicate that the prevalence of type 2 diabetes among people aged over 60 years is close to $10 \%$ (2). In addition, the probability of developing diabetic retinopathy is nearly $30 \%$ among patients with diabetes for more than 20 years (3). To date, there is no very effective method for treating the disease.

Oxidative stress and signaling pathways activated by stress are involved in the occurrence and development of diabetic retinopathy. Studies have shown that (3) increase in oxidative stress can be observed both in the retina of diabetic individuals and in the retinal endothelial cells and pericytes cultured in high glucose. Oxidative stress can damage the retinal endothelial cells and pericytes, resulting in pathological changes of the retina. Probucol has strong anti-oxidative stress and hypolipidemic effects, clinical application of probucol in the treatment of diabetic nephropathy and prevention and treatment of atherosclerosis associated with type 2 diabetes has achieved preferable results $(4,5)$. However, there is scarce literature on pobucol for the treatment of diabetic retinopathy.

The primary purpose of this study was to investigate the effect of probucol in the treatment of diabetic retinopathy and analyze its impact on its hemodynamics, rheology and blood lipid. 
Table I. Demographic data for the patients in the two groups.

\begin{tabular}{|c|c|c|c|c|c|c|c|c|}
\hline Group & $\mathrm{N}$ & $\begin{array}{l}\text { Male/ } \\
\text { female }\end{array}$ & $\begin{array}{c}\text { Age } \\
\text { (years) }\end{array}$ & $\begin{array}{c}\text { Duration of } \\
\text { diabetes (years) }\end{array}$ & $\begin{array}{c}\text { With } \\
\text { microangioma }\end{array}$ & $\begin{array}{c}\text { With hemorrhage } \\
\text { spot }\end{array}$ & $\begin{array}{l}\text { With yellow and } \\
\text { white exudate }\end{array}$ & $\begin{array}{l}\text { With macular } \\
\text { edema }\end{array}$ \\
\hline Observation & 40 & $28 / 12$ & $58.2 \pm 3.1$ & $19.2 \pm 2.1$ & 23 & 7 & 5 & 5 \\
\hline Control & 40 & 29/11 & $58.3 \pm 3.0$ & & 24 & 6 & 6 & 4 \\
\hline
\end{tabular}

\section{Patients and methods}

Patient data. A total of 80 patients with diabetic retinopathy who were treated in the Ninth People's Hospital of Chongqing (Chongqing, China) from January 2015 to August 2016 were selected, and all the patients were confirmed by glucose tolerance test, glucose determination and ophthalmoscopy. Before enrollment, signed informed consent of the patients was obtained and the research was approved by the Ethics Committee of The Ninth People's Hospital of Chongqing. Signed written informed consents were obtained from the patients and/or guardians. Patients with one of the following events were excluded: complicated with serious cardiac and pulmonary dysfunction, associated with type 1 diabetes, complicated with secondary hypertension, associated with chronic obstructive pulmonary disease, complicated with heart failure, associated with severe hepatic or renal dysfunction, complicated with coagulation disorders, associated with nephrotic syndrome, use of lipid regulating drugs within 3 months before enrollment, use of drugs affecting the hemodynamics within 3 months before enrollment and refusal to sign for enrollment. All the patients were divided into two groups by random number table, with 40 patients in each group. In observation group, there were 28 men and 12 women aged 40-80 years, with an average age of 58.2 \pm 3.1 years; the duration of diabetes was 10-35 years, with an average duration of $19.2 \pm 2.1$ years; the duration of complicated retinopathy was 1-6 years, with an average duration of $3.1 \pm 0.2$ years; there were 23 cases of microangioma, 7 cases of hemorrhage spot, 5 cases of yellow and white exudate and 5 cases of macular edema. In control group, there were 29 men and 11 women aged 40-80 years, with an average age of 58.3 \pm 3.0 years; the duration of diabetes was 10-35 years, with an average duration of $19.3 \pm 2.0$ years; the duration of complicated retinopathy

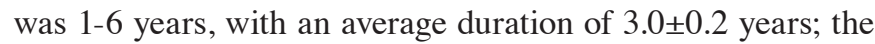
number of cases of microangioma, hemorrhage spot, yellow and white exudate as well as macular edema was $24,6,6$ and 4 , respectively. The differences in gender, age, duration of diabetes, duration of complicated retinopathy and clinical manifestations of fundus lesions between the two groups were not statistically significant $(\mathrm{P}>0.05)$ (Table I).

Therapeutics for two groups. Dietary control, exercise therapy and oral hypoglycemic drugs were applied to all the enrolled patients to treat diabetes. Whether subcutaneous injection of insulin was performed or not was determined by the change of blood glucose. It was generally recommended that fasting blood glucose be controlled within $7.0 \mathrm{mmol} / \mathrm{l}$ and $2 \mathrm{~h}$ postprandial blood glucose within $11.1 \mathrm{mmol} / \mathrm{l}$ and glycosylated hemoglobin be regulated $<7.0 \%$. Meanwhile, health education about diabetes in patients was strengthened. Control group was given metformin and acarbose to control the blood glucose, and observation group was treated with probucol $(0.375 \mathrm{~g}$ twice a day) (Shanghai First Pharma Ltd., Shanghai, China) on basis of blood glucose control.

Observation indicators. Outpatient follow-up was performed to all the patients for 6 months. Among the blood rheology, the changes in blood viscosity and erythrocyte aggregation indexes at different time points before and after intervention in the two groups were compared. Mean blood flow velocities in renal artery, renal artery pulse indexes and renal artery resistance indexes at different time points were recorded. Changes in blood lipid of the two groups before and after intervention were compared, and the rate of complications during the treatment was calculated.

Detection methods. The measurement of whole blood viscosity (at high and low shear rates) and plasma viscosity were performed using LG-R-80F series automated hematology analyzer manufactured by Beijing Steellex Scientific Instrument Co. (Beijing, China), and SYSMEX CA-7000 automatic blood biochemical analyzer was used to measure the erythrocyte aggregation index. Color Doppler ultrasound (Bioson Corp., Beijing, China) was utilized to detect renal blood flow. The patients were in the left lateral position and right lateral position during the examination. The flow spectrain bilateral main renal arteries, segmental renal arteries and middle sections of renal interlobar arteries were recorded, respectively, to calculate the mean blood flow velocities as well as the pulse indexes and resistance indexes. The values of the above mentioned examinations were based on the mean values of the main renal arteries, segmental renal arteries and renal interlobar arteries, so that the mean of the measured values in the bilateral main renal arteries was taken as the enrollment data. As for indexes related to blood lipid, total cholesterol (TC), triglyceride (TG), low density lipoprotein cholesterol (LDL-C) and high-density lipoprotein cholesterol (HDL-C) were detected using Aeroset series automatic biochemistry analyzers (Abbott, Abbott Park, IL, USA). Samples collection method was that the venous blood was taken when the patients were enrolled and fasting venous blood was taken in the morning 6 months after intervention.

Statistical analysis. SPSS 21.0 (IBM Corp., New York, NY, USA) was used for statistical processing. The measurement data are presented as mean \pm standard deviation, and the enumeration data were calculated at \%; t-test was used for mean comparison between groups, analysis of variance of repeated measures was performed for mean comparison within 
Table II. Comparisons of plasma viscosity changes in blood rheology in two groups before and after intervention (mPa/s, mean $\pm \mathrm{SD})$.

\begin{tabular}{llccc}
\hline Group & & $\begin{array}{c}\text { Whole blood viscosity } \\
\text { at high shear rate }\end{array}$ & $\begin{array}{c}\text { Whole blood viscosity } \\
\text { at low shear rate }\end{array}$ & Plasma viscosity \\
\hline Observation & Before intervention & $5.99 \pm 0.09$ & $12.03 \pm 0.08$ & $1.85 \pm 0.03$ \\
& After intervention & $5.56 \pm 0.03^{\mathrm{a}, \mathrm{b}}$ & $10.82 \pm 0.06^{\mathrm{a}, \mathrm{b}}$ & $1.61 \pm 0.01^{\mathrm{a}, \mathrm{b}}$ \\
\multirow{3}{*}{ Control } & Before intervention & $5.98 \pm 0.10$ & $12.04 \pm 0.08$ & $1.86 \pm 0.03$ \\
& After intervention & $5.73 \pm 0.06$ & $11.12 \pm 0.05$ & $1.75 \pm 0.02$ \\
\hline
\end{tabular}

${ }^{\mathrm{a}} \mathrm{P}<0.05$ indicates comparisons with those before intervention; ${ }^{\mathrm{b}} \mathrm{P}<0.05$ indicates comparisons with those in control group.

the group, and $\chi^{2}$ test was used for rate comparison between groups. $\mathrm{P}<0.05$ suggested that the difference was statistically significant and comparable.

\section{Results}

Comparisons of plasma viscosity changes in blood rheology in two groups before and after intervention. Before intervention, the differences in whole blood viscosity at high shear rate, whole blood viscosity at low shear rate and plasma viscosity between the two groups were not statistically significant $(\mathrm{P}>0.05)$. After intervention, the whole blood viscosity at high and low shear rates and plasma viscosity in observation group were lower than those before intervention $(\mathrm{P}<0.05)$, and those indexes were lower than those in control group after intervention $(\mathrm{P}<0.05)($ Table II).

Comparisons of erythrocyte aggregation indexes at different time points during intervention in two groups. Before intervention, the erythrocyte aggregation indexes in the two groups were $4.81 \pm 0.13$ and $4.82 \pm 0.13$, respectively, and the difference was not statistically significant $(\mathrm{t}=0.344, \mathrm{P}>0.05)$. The erythrocyte aggregation indexes in observation groups were $4.53 \pm 0.11,4.26 \pm 0.11$ and $3.79 \pm 0.10$ at 1 week, 1 month and 6 months after intervention, respectively, which were obviously decreased compared with those in control group $[4.73 \pm 0.12,4.46 \pm 0.10$ and $3.99 \pm 0.12$, respectively; $(\mathrm{t}=7.770$, $\mathrm{t}=19.995$ and $\mathrm{t}=8.098$, respectively, $\mathrm{P}<0.05$ )] (Fig. 1).

Comparisons of mean blood flow velocities in renal artery at different time points during intervention in two groups. Before intervention, the mean blood flow velocities in renal artery in the two groups were $23.36 \pm 1.81 \mathrm{~cm} / \mathrm{sec}$ and $23.37 \pm 1.82 \mathrm{~cm} / \mathrm{sec}$, respectively, and the difference was not statistically significant $(\mathrm{t}=0.025, \mathrm{P}>0.05)$. The mean blood flow velocities in renal artery in observation group were $25.62 \pm 1.66 \mathrm{~cm} / \mathrm{sec}, 28.67 \pm 1.32 \mathrm{~cm} / \mathrm{sec}$ and $30.56 \pm 1.05 \mathrm{~cm} / \mathrm{sec}$ at 1 week, 1 month and 6 months after intervention, respectively, which were remarkably higher than those in control group $[24.32 \pm 1.53 \mathrm{~cm} / \mathrm{sec}, 25.63 \pm 1.38 \mathrm{~cm} / \mathrm{sec}$ and $26.67 \pm 1.25 \mathrm{~cm} / \mathrm{sec}$, respectively; $(\mathrm{t}=3.642, \mathrm{t}=10.068$ and $\mathrm{t}=15.071$, respectively, $\mathrm{P}<0.05)]$ (Fig. 2).

Comparisons of renal artery pulse indexes at different time points during intervention in two groups. Before intervention,

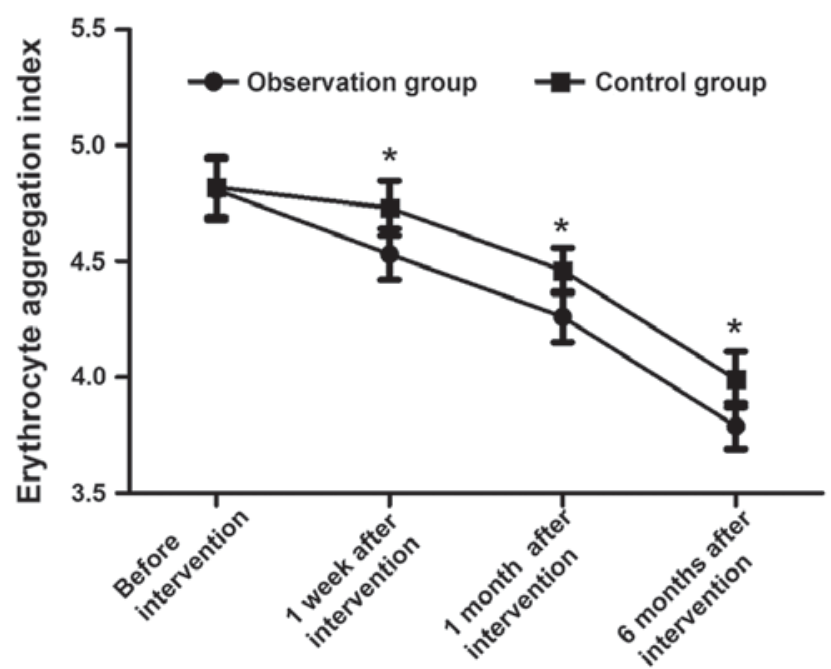

Figure 1. Comparisons of erythrocyte aggregation indexes at different time points during intervention in two groups. At 1 week, 1 month and 6 months after intervention, the erythrocyte aggregation indexes in observation group are obviously increased compared with those in control group (" $\mathrm{P}<0.05$ vs. control group).

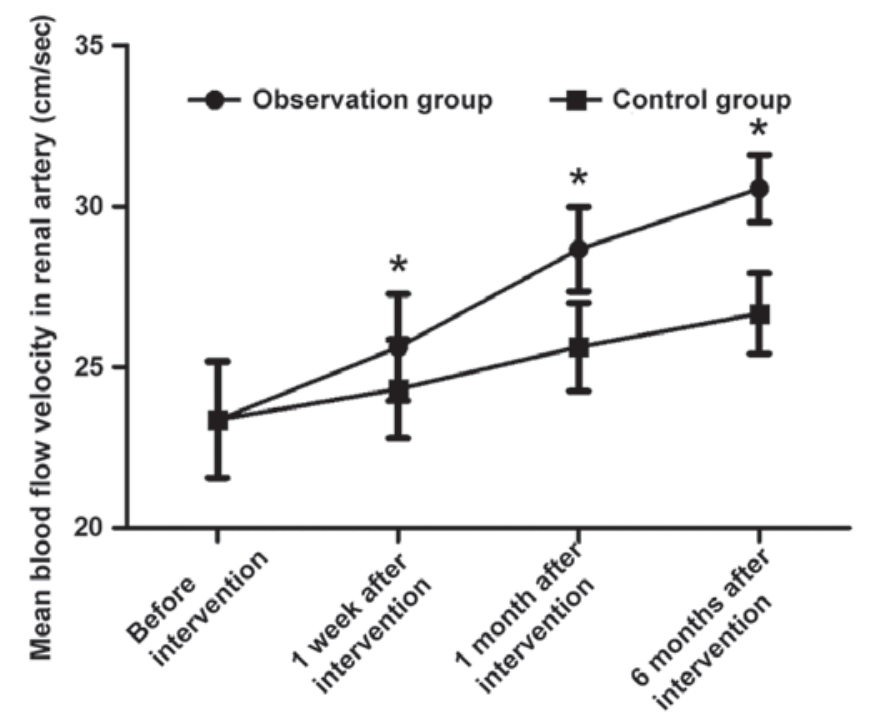

Figure 2. Comparisons of mean blood flow velocities in renal artery at different time points during intervention in two groups. At 1 week, 1 month and 6 months after intervention, the mean blood flow velocities in renal artery in observation group are remarkably higher than those in control group ( $\mathrm{P}<0.05$ vs. control group). 
Table III. Comparisons of changes in blood lipid in the two groups before and after intervention (mmol/l, mean \pm SD).

\begin{tabular}{llllll}
\hline Group & & \multicolumn{1}{c}{ TC } & \multicolumn{1}{c}{ TG } & \multicolumn{1}{c}{ LDL-C } & HDL-C \\
\hline Observation & Before intervention & $6.13 \pm 0.02$ & $2.35 \pm 0.02$ & $3.5 \pm 0.03$ & $1.32 \pm 0.02$ \\
& After intervention & $4.61 \pm 0.01^{\mathrm{a}, \mathrm{b}}$ & $1.45 \pm 0.01^{\mathrm{a}, \mathrm{b}}$ & $2.3 \pm 0.02^{\mathrm{a}, \mathrm{b}}$ & $1.49 \pm 0.03^{\mathrm{a}, \mathrm{b}}$ \\
Control & Before intervention & $6.15 \pm 0.03$ & $2.36 \pm 0.03$ & $3.6 \pm 0.03$ & $1.33 \pm 0.02$ \\
& After intervention & $5.51 \pm 0.01$ & $1.85 \pm 0.01$ & $2.7 \pm 0.02$ & $1.39 \pm 0.02$ \\
\hline
\end{tabular}

${ }^{\mathrm{a}} \mathrm{P}<0.05$ indicates comparisons with those before intervention; ${ }^{\mathrm{b}} \mathrm{P}<0.05$ indicates comparisons with those in control group.

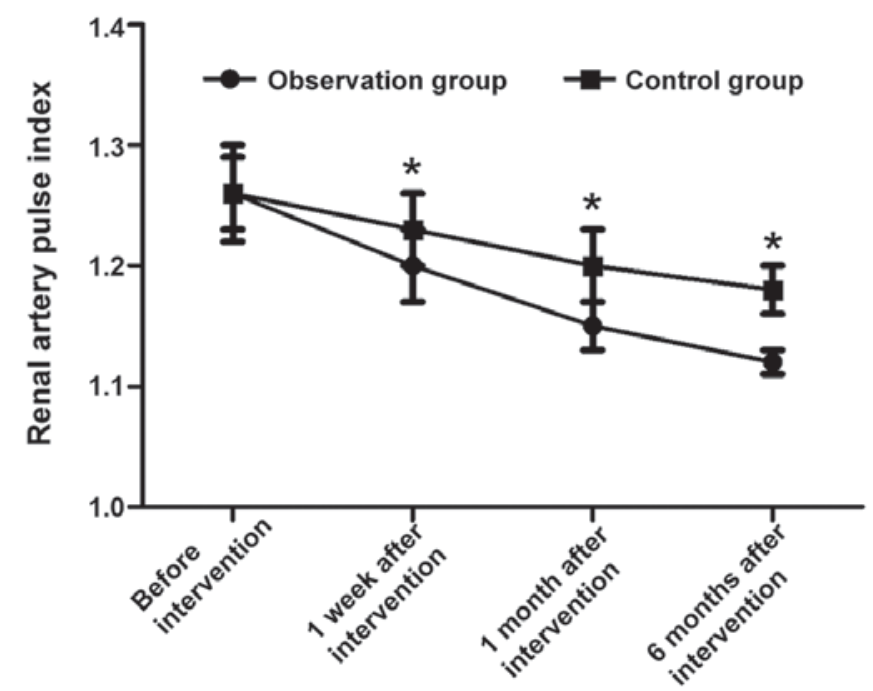

Figure 3. Comparisons of renal artery pulse indexes at different time points during intervention in two groups. At 1 week, 1 month and 6 months after intervention, the renal artery pulse indexes in observation group are lower than those in control group ( $\mathrm{P}<0.05$ vs. control group).

the renal artery pulse indexes in the two groups were $1.26 \pm 0.04$ and $1.26 \pm 0.03$, respectively, and the difference was not statistically significant $(\mathrm{t}=0.000, \mathrm{P}>0.05)$. The renal artery pulse indexes in observation group were $1.20 \pm 0.03,1.15 \pm 0.02$ and $1.12 \pm 0.01$ at 1 week, 1 month and 6 months after intervention, respectively, which were notably lower than those in control group $[1.23 \pm 0.03,1.20 \pm 0.03$ and $1.18 \pm 0.02$, respectively; $(\mathrm{t}=4.472, \mathrm{t}=8.771$ and $\mathrm{t}=16.971$, respectively, $\mathrm{P}<0.05)]($ Fig. 3$)$.

Comparisons of renal artery resistance indexes at different time points during intervention in two groups. Before intervention, the renal artery resistance indexes in the two groups were $0.80 \pm 0.03$ and $0.81 \pm 0.03$, respectively, and the difference was not statistically significant $(\mathrm{t}=1.491, \mathrm{P}>0.05)$. The renal artery resistance indexes in observation group were $0.73 \pm 0.01$, $0.65 \pm 0.01$ and $0.57 \pm 0.01$ at 1 week, 1 month and 6 months after intervention, respectively, which were much lower than those in control group $[0.79 \pm 0.01,0.70 \pm 0.01$ and $0.61 \pm 0.01$, respectively; $(\mathrm{t}=26.833, \mathrm{t}=22.361$ and $\mathrm{t}=17.889$, respectively, $\mathrm{P}<0.05)]$ (Fig. 4).

Comparisons of changes in blood lipid in the two groups before and after intervention. By comparing the levels of TC, TG, LDL-C and HDL-C before intervention, the differences

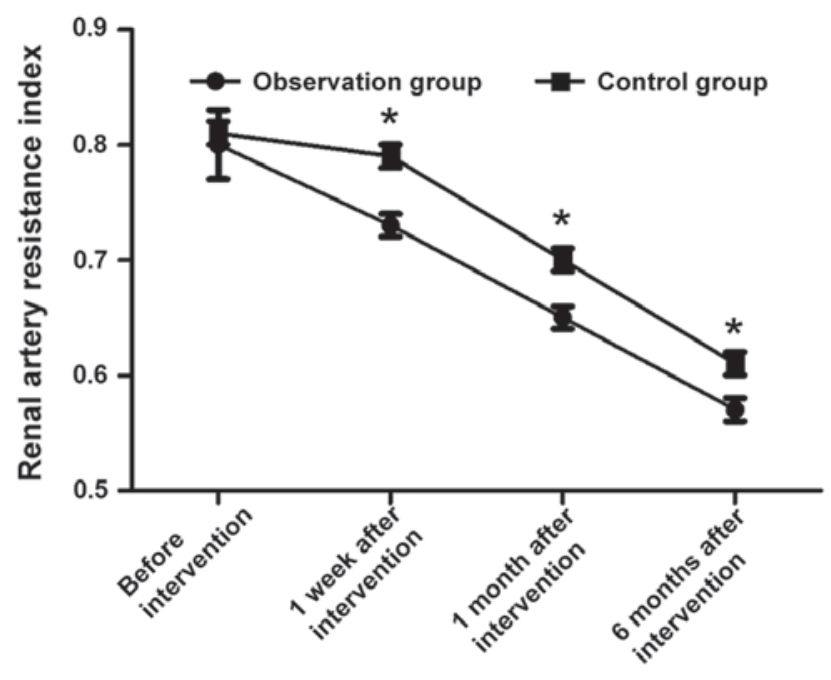

Figure 4. Comparisons of renal artery resistance indexes at different time points during intervention in two groups. At 1 week, 1 month and 6 months after intervention, the renal artery resistance indexes in observation group are much lower than those in control group ( $\mathrm{P}<0.05$ vs. control group).

between the two groups were not statistically significant $(\mathrm{P}>0.05)$. In observation group, the levels of $\mathrm{TC}, \mathrm{TG}$ and LDL-C after intervention were decreased compared with those before intervention $(\mathrm{P}<0.05)$, while the level of HDL-C was increased $(\mathrm{P}<0.05)$. After intervention, the levels of $\mathrm{TC}$, TG and LDL-C in observation group were lower than those in control group $(\mathrm{P}<0.05)$, while the HDL-C level was higher $(\mathrm{P}<0.05)$ (Table III).

Comparisons of complications during treatment in the two groups. During the treatment, the total incidence of phlebitis, chills, fever, rash and maculopapule in observation group was obviously lower than that in control group $(\mathrm{P}<0.05)$ (Table IV).

\section{Discussion}

Diabetic retinopathy, one of the most common microvascular diseases of advanced diabetes, is a specific ocular fundus vascular lesion and a serious complication of diabetes (6). Its diagnosis and typing is based on whether there is retinal neovascularization. Patients without retinal neovascularization are integrated into simple-type or background-type diabetic retinopathy (7), while patients with retinal neovascularization are integrated into proliferative diabetic retinopathy (8). With 
Table IV. Comparisons of complications during treatment in the two groups $(\mathrm{n}, \%)$.

\begin{tabular}{lcccc}
\hline Items & Phlebitis & $\begin{array}{c}\text { Chills and } \\
\text { fever }\end{array}$ & $\begin{array}{c}\text { Rash and } \\
\text { maculopapule }\end{array}$ & $\begin{array}{c}\text { Total } \\
\text { incidence }\end{array}$ \\
\hline Observation & 0 & 1 & 1 & $2(5.0 \%)$ \\
Control & 2 & 3 & 5 & $10(25.0 \%)$ \\
$\chi^{2}$ value & - & 4.804 & & \\
P-value & - & 0.028 & & \\
\hline
\end{tabular}

regard to treatment of this disease, patients with early lesions generally do not need specific treatment. Enhanced clinical observation and follow-up is sufficient, of which observation of changes in clinical ocular symptoms and control of blood glucose should be conducted (9) to prevent and decrease further development of ocular diseases. When complicated ocular fundus hemorrhage and neovascularization occur, fluoresce in angiography should be performed in time for diagnosis confirmation so as to exclude non-perfused regions in ocular fundus (10). Alternatively, panretinal photo coagulation or even vitrectomy can be implemented in the early stage to avoid irreversible changes of vision acuity in patients (11). So far, however, there is no particularly efficient agent in drug therapies, especially the medical treatment for patients in early and middle stage, in clinical practices (12).

In this study, observation group was given probucol therapy on the basis of conventional glycemic control. By comparing the changes in the blood rheology in the two groups before and after intervention, it was found that the whole blood viscosities at high and low shear rates as well as plasma viscosity in observation group were lower than those before probucol intervention and those in control group. Moreover, by comparing the erythrocyte aggregation indexes at different time points during the intervention in the two groups, it was discovered that the erythrocyte aggregation indexes in observation group were obviously increased compared with those in control group at 1 week, 1 month and 6 months after intervention. It suggests that application of probucol in the treatment of diabetic nephropathy can remarkably improve the rheological indexes of the patients, reduce blood viscosity and raise the blood flow velocity in renal artery. Moreover, in terms of the mean blood flow velocities in renal artery, renal artery pulse indexes and resistance indexes at different time points during the intervention, it was found that the mean blood flow velocities in renal artery in observation group were remarkably higher than those in control group at 1 week, 1 month and 6 months after intervention, while the renal artery resistance indexes and pulse indexes in observation group were lower than those in control group in the same period. It indicates that use of probucol therapy for treatment of diabetic retinopathy can ameliorate the hemodynamic indexes of the patients, improve blood flow in renal arteries and decrease vascular resistance. By comparing the blood lipid changes before and after intervention in the two groups, it showed that in the observation group, the levels of TC, TG and LDL-C after intervention were decreased compared with those before intervention $(\mathrm{P}<0.05)$, while the HDL-C level was increased. After intervention, the levels of TC, TG and LDL-C in observation group were lower than those in control group $(\mathrm{P}<0.05)$, while the HDL-C level was higher. It suggests that for patients with diabetic retinopathy, probucol therapy can better regulate the metabolism of blood lipid and lower the blood lipid level. Finally, through comparison of the complications during the treatment in the two groups, it was found that the total incidence of phlebitis, chills, fever, rash and maculopapule in observation group was obviously lower than that in control group during the treatment. It proves that probucol therapy has high safety.

Probucol can effectively decrease blood lipid and ameliorate the blood rheology and hemodynamics (13). On treating diabetic retinopathy, it can improve the blood flow in the retinal vessels and reduce formation of thrombus by means of inhibiting platelet aggregation and thromboxane release produced by it in the body (14). Moreover, the drug can adjust the prostaglandin level in the body and reduce retinal vasoconstriction. Furthermore, it can lower the fibrinogen level in plasma (15), improve coagulation function of the body, regulate fibrinolytic function and decrease the blood viscosity (16). Probucol can also reduce endothelin release in the body, thus increasing the level of nitric oxide in the blood vessels (17), promoting vasodilatation and ameliorating rheological indexes (18). In respect of blood lipid regulation, probucol can effectively alleviate endothelial injury and reduce platelet aggregation, which can not only have an anticoagulating effect (19), but also lower the levels of TC, TG and LDL-C in the body, thus having a hypolipidemic effect (20).

However, there are still some limitations of our study. The sample size of cases and controls is small due to the limitation of time and funds, and we will increase the sample size for further study later. The relationship between various indices of diabetic retinopathy and outpatient follow-up of the impact of probucolin was not investigated according to the severity of the disease because the sample size was not large, and we will further study the related issues in subsequent studies. In conclusion, application of probucol in treatment of diabetic retinopathy can significantly improve the hemodynamic and rheological indexes and lower blood lipid in the body.

\section{Acknowledgements}

We would like to thank Dr Wen Wei and Dr Jie Zhang for their assistance.

\section{Funding}

The present study was supported by the Chongqing Municipal Health Bureau (no. 2016MSXM145).

\section{Availability of data and materials}

All data generated or analyzed during this study are included in this published article.

\section{Authors' contributions}

HL performed the study and wrote the manuscript. MC analysed the data and revised the manuscript. All authors read and approved the final manuscript. 


\section{Ethics approval and consent to participate}

This study was approved by the Ethics Committee of The Ninth People's Hospital of Chongqing (Chongqing, China). Signed written informed consents were obtained from the patients and/or guardians.

\section{Consent for publication}

Not applicable.

\section{Competing interests}

The authors declare that they have no competing interests.

\section{References}

1. Fei YX, Wang SQ, Yang LJ, Qiu YY, Li YZ, Liu WY, Xi T, Fang WR and Li YM: Salvia miltiorrhiza Bunge (Danshen) extract attenuates permanent cerebral ischemia through inhibiting platelet activation in rats. J Ethnopharmacol 207: 57-66, 2017.

2. Bi X, Zhang K, He L, Gao B, Gu Q, Li X, Chen J and Wang J: Synthesis and biological evaluation of tanshinone IIA derivatives as novel endothelial protective agents. Future Med Chem 9: 1073-1085, 2017.

3. Sha J, Sui B, Su X, Meng Q and Zhang C: Alteration of oxidative stress and inflammatory cytokines induces apoptosis in diabetic nephropathy. Mol Med Rep 16: 7715-7723, 2017.

4. Murata Y, Sugi T, Weiss LM and Kato K: Identification of compounds that suppress Toxoplasma gondiitachyzoites and bradyzoites. PLoS One 12: e0178203, 2017.

5. Endo K, Miyashita Y, Sasaki H, Ohira M, Saiki A, Koide N, Otsuka M, Oyama T, Takeyoshi M, Ito Y, et al: Probucol delays progression of diabetic nephropathy. Diabetes Res Clin Pract 71: 156-163, 2006

6. Ojha S, Balaji V, Sadek B and Rajesh M: Beneficial effects of phytochemicals in diabetic retinopathy: Experimental and clinical evidence. Eur Rev Med Pharmacol Sci 21: 2769-2783, 2017.

7. Qin YL, Chen L, He W, Su M, Jin Q, Fang Z, Ouyang PK and Guo K: Continuous synthesis and anti-myocardial injury of tanshinone IIA derivatives. J Asian Nat Prod Res 8: 1-9, 2017.

8. Yao NW, Lu Y, Shi LQ, Xu F and Cai XH: Neuroprotective effect of combining tanshinone IIA with low-dose methylprednisolone following acute spinal cord injury in rats. Exp Ther Med 13: 2193-2202, 2017

9. Chen PX, Zhang YL, Xu JW, Yu MH, Huang JH, Zhao L and Zhou WL: Sodium tanshinone IIA sulfonate stimulated Cl-secretion in mouse trachea. PLoS One 12: e0178226, 2017.
10. Li X, Li Z,Li X, Liu B and Liu Z: Mechanisms of Tanshinone IIA inhibits malignant melanoma development through blocking autophagy signal transduction in A375 cell. BMC Cancer 17: 357, 2017.

11. Chen F, Li H, Zhu G, Chen X and Tang Z: Sodium tanshinone IIA sulfonate improves inflammation, aortic endothelial cell apoptosis, disseminated intravascular coagulation and multiple organ damage in a rat heat stroke model. Mol Med Rep 16: 87-94, 2017.

12. Tang LM, Wang LX, Wang ZY, Sun LF, Pan XD and Pan GQ: Tanshinone IIA ameliorates lead $(\mathrm{Pb})$-induced cognitive deficits and oxidative stress in a rat pup model. Bratisl Lek Listy 118: 196-201, 2017.

13. Parthasarathy S, Young SG, Witztum JL, Pittman RC and Steinberg D: Probucol inhibits oxidative modification of low density lipoprotein. J Clin Invest 77: 641-644, 1986.

14. Endo K, Miyashita Y, Sasaki H, Ebisuno M, Ohira M, Saiki A, Koide N, Oyama T, Takeyoshi M and Shirai K: Probucol and atorvastatin decrease urinary 8-hydroxy-2'-deoxyguanosine in patients with diabetes and hypercholesterolemia. J Atheroscler Thromb 13: 68-75, 2006.

15. Ma J, Zhao S, Gao G, Chang H, Ma P and Jin B: Probucol protects against asymmetric dimethylarginine-induced apoptosis in the cultured human brain microvascular endothelial cells. J Mol Neurosci 57: 546-553, 2015.

16. Mooranian A, Negrulj R, Arfuso F and Al-Salami H: Multicompartmental, multilayered probucol microcapsules for diabetes mellitus: Formulation characterization and effects on production of insulin and inflammation in a pancreatic $\beta$-cell line. Artif Cells Nanomed Biotechnol 44: 1642-1653, 2016.

17. Zhong JK, Guo ZG, Li C, Wang ZK, Lai WY and Tu Y: Probucol alleviates atherosclerosis and improves high density lipoprotein function. Lipids Health Dis 10: 210, 2011.

18. Santos DB, Peres KC, Ribeiro RP, Colle D, dos Santos AA, Moreira EL, Souza DO, Figueiredo CP and Farina M: Probucol, a lipid-lowering drug, prevents cognitive and hippocampal synaptic impairments induced by amyloid $\beta$ peptide in mice. Exp Neurol 233: 767-775, 2012.

19. Braun A, Zhang S, Miettinen HE, Ebrahim S, Holm TM, Vasile E, Post MJ, Yoerger DM, Picard MH, Krieger JL, et al: Probucol prevents early coronary heart disease and death in the high-density lipoprotein receptor SR-BI/apolipoprotein E double knockout mouse. Proc Natl Acad Sci USA 100: 7283-7288, 2003.

20. Yakushiji E, Ayaori M, Nishida T, Shiotani K, Takiguchi S, Nakaya K, Uto-Kondo H, Ogura M, Sasaki M, Yogo M, et al: Probucol-Oxidized products, spiroquinone and diphenoquinone, promote reverse cholesterol transport in mice. Arterioscler Thromb Vasc Biol 36: 591-597, 2016. International (CC BY-NC-ND 4.0) License. 